\title{
O FENÔMENO BULLYING: DIFERENÇAS ENTRE MENINOS E MENINAS ${ }^{1}$
}

\author{
Fernanda Silva ${ }^{2}$ \\ Denise Dascanio ${ }^{3}$
}

Tânia Gracy Martins do Valle ${ }^{4}$

\section{Resumo}

O fenômeno bullying caracteriza-se por agressões sempre em desigualdade de poder e envolve atos violentos. Este estudo teve por objetivo identificar os tipos de bullying (físico, verbal, psicológico, material, virtual ou sexual) mais prevalente na população estudada e comparar o bullying entre adolescentes do sexo masculino e feminino. Utilizou-se para a coleta de dados, um questionário, elaborado pela pesquisadora. Participaram 309 alunos, 142 do sexo masculino e 167 do sexo feminino, do $6^{\circ}$ ao $8^{\circ}$ ano de duas escolas, uma estadual e outra municipal. Os resultados apontaram 27\% dos participantes envolveram-se em episódios de bullying e que o tipo de bullying mais prevalente foi o verbal, sendo apontado por $92 \%$ das meninas e $84 \%$ dos meninos; seguido do psicológico, assinalado por $70 \%$ das meninas e $53 \%$ dos meninos. O bullying físico, contou com $46 \%$ de relatos femininos e $44 \%$ masculinos, o material foi mencionado por $27 \%$ das meninas e $16 \%$ dos meninos. No bullying tipo sexual houve maior diferença entre os sexos, sofrido por $38 \%$ das meninas e por $16 \%$ dos meninos. Somente $13 \%$ das meninas e $12 \%$ dos meninos, mencionaram sofrer o bullying virtual. Corroborando com pesquisas da área, no presente estudo a maior porcentagem de vítimas foi

\footnotetext{
${ }^{1}$ Este estudo é parte da pesquisa de mestrado da primeira autora intitulada: O fenômeno bullying em escolares do Ensino Fundamental, sob orientação da última e contou com a colaboração da autora (3) em diferentes etapas de sua elaboração.

${ }^{2}$ Doutoranda em Educação Especial. UNESP, Universidade Estadual Júlio de Mesquita Filho - Marília. Mestre em Psicologia do Desenvolvimento e Aprendizagem, UNESP - Bauru. Endereço: Rua das Jaqueiras 2-33, Núcleo Residencial Pres. Geisel, CEP 17033-120. Bauru, SP, Brasil. Endereço eletrônico: fermeninasilva@hotmail.com

${ }^{3}$ Professor Doutor, Departamento de Ciências Humanas, UNIP, Universidade Paulista - Campus Bauru. Endereço: Rua Sebastião Pregnolato, 6-70, ap. 14, bloco C. Jardim dos Duques, CEP 17047-145. Bauru, SP, Brasil. Endereço eletrônico: psicode21@ yahoo.com.br

${ }^{4}$ Professor Doutor. Departamento de Psicologia, Faculdade de Ciências, UNESP - Campus Bauru. Endereço: Av. Eng. Luiz Edmundo Carrijo Coube, nº 14-01, Bairro: Vargem Limpa, CEP 17033-360 - Bauru, SP, Brasil. Endereço eletrônico: tgvalle@uol.com.br
} 
SILVA, F; DASCANIO, D; VALLE, T. G. M.

do sexo feminino e divergindo da literatura as meninas relataram ser agredidas verbalmente mais por meninos do que por meninas.

Palavras-chave: Bullying Escolar; Violência entre Pares; Diferença entre Sexos

\section{INTRODUÇÃO}

A origem dos estudos sobre o bullying remonta o ano de 1982, na Noruega, quando três meninos, com idade entre 10 e 14 anos suicidaram-se, como resultado de assédio de seus pares. A partir desse episódio, o pesquisador norueguês, Dan Olweus, da Universidade de Berger, que já estudava o fenômeno desde a década de 70, deu início a um estudo para investigar a frequência e causas que levavam à prática do bullying. Olweus reuniu 84 mil estudantes, quase 400 professores e aproximadamente 1000 pais de alunos. Ao final de sua pesquisa, constatou que um em cada sete alunos, encontrava-se envolvido em casos de bullying, como agressor ou vítima. A partir desse resultado, o pesquisador mobilizou a sociedade ao iniciar uma campanha nacional contra o bullying. O programa, que recebeu o apoio do governo da Noruega, conseguiu reduzir a ocorrência dos fatos de bullying em 50\%, resultado que incentivou países como Inglaterra, Canadá e Portugal a adotarem práticas semelhantes (OLWEUS, 2006).

Na língua portuguesa não há uma tradução exata da palavra bullying, mas Calhau (2010) o define como abuso, intimidação e vitimação, desde que ocorra sem motivação e de forma repetitiva. No Brasil, adotou-se o termo bullying, que é utilizado na maioria dos países. Sua definição é compreendida como um subconjunto de comportamentos agressivos, sendo de natureza repetitiva e caracterizada por um desequilíbrio de poder. Fante (2011) comenta que para alguns pesquisadores são necessários no mínimo três ataques contra a vítima no decorrer do ano para ser configurado como bullying. Na mesma direção o pesquisador Olweus (2006), afirma que o bullying ocorre quando ações violentas são reproduzidas de três a cinco vezes ao ano.

Olweus (1993); Almeida, Lisboa e Caurcel (2007), caracterizam este tipo de violência, quando o indivíduo é perseguido, aborrecido, agredido ou vitimizado repetida e frequentemente, por meio de ações negativas por parte de um ou mais colegas, que se 
utilizam do próprio corpo ou objetos para provocar danos ou desconfortos de modo intencional. Pereira (2002) descreve o bullying como uma forma de comportamento agressivo, geralmente maldosa, deliberada e com frequência persistente, podendo durar semanas, meses ou anos, sendo as vítimas sempre incapazes de se defender. O autor ainda acrescenta que, três características são básicas para diferenciar o bullying de outros tipos de violência: o mal causado não resulta de provocações; as intimidações são regulares, os agressores em geral são mais fortes e violentos e as vítimas não estão preparadas para se defender.

Para Santos (2009), o bullying funciona como uma epidemia invisível em que atitudes aparentemente despretensiosas, "brincadeiras" e apelidos, magoam profundamente o ser humano, deixando marcas como a desmoralização, a humilhação e a perda da dignidade. Essas podem impedir o desenvolvimento saudável da autoestima e a construção da sua identidade.

Tognetta (2008) e Lopes Neto (2011) utilizam os termos “alvos de bullying”, para caracterizar as vítimas, aqueles que sofrem algum tipo de violência, sendo ela direta ou indireta, e “autores de bullying”, como aqueles que violentam direta ou indiretamente, de forma repetitiva e agressiva. "Testemunhas", são os que assistem aos episódios de violência ativa ou passivamente. Nogueira (2007) traz definições de papéis bem semelhantes a esses autores, porém denomina aluno-alvo típico (alvo); aluno-alvo provocador (alvo); aluno-alvo agressor (alvo) ou aluno-alvo e autor (autor); aluno-autor ou aluno-agressor (autor) e aluno espectador ou testemunha (testemunha).

Neste estudo, optou-se em utilizar as expressões: "vítima" (alvo), "agressor" (autor) e "espectador" (testemunha) utilizadas respectivamente por Calhau (2010), Silva (2010) e Fante (2011). As características das pessoas envolvidas com o fenômeno bullying são especificadas abaixo conforme descrições oferecidas por Silva (2010) e Fante (2011) sendo: Vítima típica - geralmente é aquele indivíduo que se mostra frágil fisicamente, não se defende e possui pouca habilidade de socialização. Geralmente são pessoas gordas, baixas ou alta demais, que usam óculos ou com alguma deficiência; Vítima provocadora - sem perceber ela provoca situações que acabam se revertendo contra si; Vítima agressora reproduz os maus-tratos como forma de compensação, sendo vítima usa essa "desculpa" para agredir os colegas; Agressor - possui traços de desrespeito e maldade, age em grupo ou 
sozinho, impõe liderança para levar vantagens e Espectador- que testemunha os episódios e geralmente não se envolve, seja para socorrer ou buscar ajuda.

Alguns autores classificam o bullying somente em duas categorias, o direto e o indireto. O modo direto configura-se no uso de apelidos, agressões físicas, roubos, atitudes sexuais forçadas, quebra de objetos, expressões ou gestos que geram mal-estar as vítimas, está relacionado aos tipos físico, material e sexual, sendo geralmente praticado por meninos. O modo indireto compreende atitudes de indiferença, isolamento, difamação, exclusão e espalhar boatos, está relacionado aos tipos verbal, psicológico e virtual, sendo mais adotado por meninas (OLWEUS, 1993; LOPES NETO, 2005; GÓMEZ SANABRIA et al., 2007; SEIXAS, 2009).

No Brasil, até a presente data, não existe legislação nacional específica sobre bullying. Encontra-se em tramitação no Congresso, uma Campanha Nacional de combate ao bullying nas escolas. Há no Estado de São Paulo a Lei 14.957, de 16 de julho de 2009, que versa sobre medidas de conscientização, prevenção e combate ao bullying nas escolas, porém é na Lei 14.651/09, de Santa Catarina (2009), que se encontram definições mais completas sobre esse fenômeno, configurado como atitudes agressivas, repetitivas, que causam sofrimento e são executadas em uma relação de desigualdade de poder. No artigo $3^{\circ}$, os tipos de bullying são categorizados em:

- $\quad$ Físico (bater, beliscar, ferir, empurrar, agredir);

- Verbal (apelidar, gozar, insultar);

- Psicológico/Moral (intimidar, ameaçar, perseguir, ignorar, aterrorizar, excluir, humilhar, difamar, caluniar, discriminar, tiranizar);

- Material (roubar, destruir pertences materiais e pessoais);

- Virtual (insultar, discriminar, difamar, humilhar, ofender por meio da Internet e/ou aparelho celular);

- Sexual (Abusar, violentar, assediar, insinuar).

Silva (2010), explica que existem 6 tipos de bullying (físico, verbal, psicológico, material, sexual e virtual), e salienta que todos se assemelham no que diz respeito a ferir a integridade do outro. Pereira (2002), afirma que o bullying pode ocorrer de diferentes formas, chegando a ser muito cruel, por meio de agressão corporal, intimidação, ameaça ou isolamento; cometidas por grupos de alunos ou alunos sozinhos, que sempre procuram pares mais frágeis, que tem dificuldade de se defender ou pedir ajuda. As vítimas adquirem aversão 
à escola e principalmente da hora do recreio, quando ficam mais expostas e com menor supervisão dos adultos. Esses papéis não são estanques, e algumas vezes se invertem nas ocorrências de bullying, pois dependendo do contexto cultural ou social, o indivíduo pode ser encorajado a ser agressor ou impelido a ser vítima (FRANCISCO, 2010).

Nos estudos de diferentes autores como Olweus (1993), Lopes Neto e Saavedra (2004), Beane (2006), Calhau (2010) e Lopes Neto (2011), os resultados obtidos apontam para as consequências drásticas na vida das vítimas do bullying, que vão desde medo; sequelas emocionais e sentimentos negativos; baixa autoestima; falta de concentração; aversão a escola; estresse; doenças imunológicas e dores de cabeça; até depressão e tentativa de suicídio.

Baldry e Farrington (2000) realizaram estudo com 113 participantes italianos do sexo feminino e 125 do sexo masculino com idades entre 11 e 14 anos. Observaram que a maior frequência do bullying ocorre entre os meninos e é de forma direta, com o uso de violência física ou ameaças e com as meninas ocorre mais em sua forma indireta, com agressões verbais e difamações.

Esperon (2004) descreve seu estudo piloto que aconteceu em 2001, no qual 124 alunos de sexo feminino e 132 do sexo feminino, de 10 a 19 anos, da cidade de Arrio do Meio, RS, responderam a um questionário. Seu objetivo foi verificar a prevalência de bullying entre estudantes, idade mais atingida, participação ativa/ passiva, entre outros itens. Os resultados demonstraram que alguns sintomas são comuns em vítimas de bullying, destacando-se: irritabilidade, alterações de humor, cefaleia, dor abdominal e pressão alta. $\mathrm{O}$ total de envolvidos em bullying foi de $65 \%$, sendo a maioria meninos. Obteve informações sobre o bullying ativo, mais frequente entre os meninos (20\%) do que entre as meninas $(11,3 \%)$ e a faixa etária mais atingida foi dos 10 aos 16 anos, com diferentes proporções.

Lisboa (2005) detectou em sua pesquisa com 253 crianças e adolescentes de 9 a 15 anos, moradores de Porto Alegre, no Brasil, que os colegas e professores apontam meninos como mais agressivos, porém eles não se percebem mais agressivos do que as meninas. Outros estudiosos também encontraram diferenças entre os sexos (SHARP, SMITH, 1991; BOULTON, UNDERWOOD, 1992; GINI, POZZOLI, 2006; TRAUTMANN, 2008; BANDEIRA, 2009), porém, entende-se que mais importante do que saber as diferenças entre os tipos de bullying que acomete meninos e meninas, é oferecer intervenções escolares para evitar conflitos e atitudes preconceituosas. 
Na Itália, Gini e Pozzoli (2006), efetivaram um estudo sobre bullying com 113 alunos (64 meninos e 49 meninas), com idade entre 6 e 10 anos. Concluíram que a masculinidade pode resultar significativamente em episódios de bullying entre crianças, mesmo estudando os sexos separadamente. A autoatribuição de traços masculinos tais como características de personalidade, pode estar presente tanto em meninos como em meninas, podendo levar as crianças a serem agressivas com os colegas. A correlação entre masculinidade e bullying pode ser explicada em termos de representações culturais, valores e expectativas sociais, reforçando o papel de liderança do valentão.

Cerca de 5 mil adolescentes escolares com a média de idade: 14,2 e 17,4 anos de 72 escolas públicas da Cidade do Cabo e Durban, África do Sul participaram da pesquisa de Liang, Flisher e Lombard (2007), completando questionários de autorrelato sobre a participação em atos de bullying, comportamentos antissociais e de risco. Os resultados apontaram que 36,3\% dos participantes envolveram-se em atos de bullying, ou como vítimas, vítimas agressoras ou agressoras. O estudo também revelou que os rapazes são mais suscetíveis a perpetração da violência e vitimação, inclusive agridem outros jovens do mesmo sexo mais novos.

Martins (2009) realizou um estudo com 572 adolescentes portugueses com idade média de 14 anos e constatou que os meninos, envolvem-se mais em atritos e justificam ser a agressão uma maneira de resolver esses conflitos. São mais vítimas e mais agressivos do que as meninas, que geralmente, envolvem-se em agressões indiretas. Ainda em Portugal, os pesquisadores Melim e Pereira (2013), concluem em seu estudo com 1.818 alunos de 10 a 18 anos, que meninos sofrem mais o bullying direto, envolvendo-se em agressões físicas e roubo de objetos e meninas envolvem-se mais em fofocas e são ignoradas pelos pares. Sobre a violência verbal, ambos se queixam, porém, as meninas são mais atingidas.

Binsfeld e Lisboa (2010) realizaram uma pesquisa com 182 crianças de ambos os sexos, que responderam questões sobre comportamento agressivo, vitimização, depressão e ansiedade e os resultados alcançados, indicaram que os agressores podem apresentar medo da impopularidade e ter pensamentos de fracasso, temendo que os próximos episódios não sejam bem sucedidos. Os estudos de Lopes Neto e Saavedra (2004); Cid et al. (2008); Fante (2011), também apontam que os agressores poderão na vida adulta, apresentar atitudes antissociais violentas, acarretando problemas familiares e dificuldades de inserção social, envolvimento com drogas, armas e desrespeito às regras e leis. 
Saúde (2011), ao realizar pesquisa sobre as características de bullying e percepção do bem-estar psicológico, com 400 alunos portugueses, sendo 200 meninos e 200 meninas do $5^{\circ}, 7^{\circ}, 9^{\circ}$ e $11^{\circ}$ ano escolar, verificou diferenças entre os sexos nos aspectos de vitimação, observação e agressão. Os meninos apresentam mais comportamentos de agressão e de vitimação, que diminuem conforme aumenta a escolaridade. Ela explica que essas diferenças ocorrem devido aos fatores cerebrais (estrutura, desenvolvimento); químicos (níveis de oxitocina meninas e serotonina - meninos); hormonais (estrógeno feminino, relacionado a proteção e cuidado; testosterona masculino, relacionado a agressão e domínio); funcionais (meninas maior competência visual e sensorial e meninos viso-espaciais); psicológicos (emoções como tristeza, compaixão em meninas e fúria, vingança em meninos), de natureza cultural (meninas podem demonstrar sentimentos, meninos devem retraí-los) e educacional (modelos parentais e estereótipos).

Frick, Menin e Tognetta (2013) relatam pesquisa que ocorreu em duas classes do Ensino Fundamental, de uma cidade do interior do Estado de São Paulo, sendo uma de $2^{\mathrm{a}}$ série (A) e outra de $4^{\circ}$ ano (B), com alunos de idade de oito a dez anos. Foram realizadas observações sistemáticas da interação dos alunos e após foi aplicado questionário sobre bullying e outros sobre conflitos pessoais. O ambiente da sala A foi caracterizado como predominantemente coercitivo com relatos de apelidos, agressões físicas, difamações e exclusão do grupo e ambiente da sala B foi tipificado como predominantemente cooperativo, porém com relatos de apelidos, formas de roubo e rejeição. Também foram analisadas as reações das professoras diante de atos de agressões entre os alunos e a conclusão foi que em um ambiente coercitivo onde os conflitos são resolvidos de modo agressivo e submisso ocorrem mais episódios de bullying.

Dada sua gravidade e frequência, atualmente o bullying tem sido objeto de atenção não apenas da sociedade, como das autoridades em geral, que visam combatê-lo em todas as suas manifestações. Assim, este trabalho almeja uma melhor compreensão do fenômeno e a sua ocorrência, numa população específica de uma cidade do interior paulista. Para isto, o objetivo deste estudo foi identificar os tipos de bullying (físico, verbal, psicológico, material, virtual ou sexual) mais prevalente na população estudada e comparar o bullying entre adolescentes do sexo masculino e feminino. 


\section{MÉTODO}

\subsection{Instrumento de pesquisa}

Um questionário com perguntas fechadas e abertas sobre bullying foi elaborado pela pesquisadora (Apêndice A) com base nos estudos de Bandeira (2009), Freire, Simão e Ferreira (2006), Rolim (2008), Oliveira (2007) e Santos (2011).

As questões foram adaptadas dos estudos citados de acordo com os objetivos deste estudo. Diversos aspectos dos questionários originais não foram considerados para este estudo, a saber: descendência, etnia/cor, questões relacionadas a drogas e álcool, sentimento ao sofrer ou ver alguém sofrendo bullying.

\subsection{Estudo piloto}

Primeiramente foi realizado um estudo piloto para adequação do questionário. Aplicou-se o instrumento em 10 alunos selecionados por meio de sorteio, sendo um de cada sala, para responder as questões, visando à adequação do instrumento. Com isto, o instrumento foi reorganizado com a alteração de algumas perguntas de forma a facilitar a compreensão pelos participantes.

\subsection{Procedimentos éticos}

Este estudo foi submetido à Plataforma Brasil, conforme Resolução 466 do Conselho Nacional de Saúde de 12/12/2012, que orienta sobre procedimentos de coleta de dados com seres humanos e foi aprovado pelo Comitê de Ética em Pesquisa (CEP) da Faculdade de Ciências da Universidade Estadual Paulista/UNESP, sob Parecer nº 645.822 de 08/05/14.

\subsection{Procedimentos de coleta de dados}

A coleta de dados aconteceu em duas escolas de Ensino Fundamental, sendo uma da Rede Pública Estadual (Escola A) e outra da Rede Municipal (Escola B), na cidade de Bauru, 
interior do Estado de São Paulo, cujos diretores aceitaram que fossem coletados os dados de forma anônima, conforme o TCLE (Termo de Consentimento Livre e Esclarecido).

A aplicação do questionário foi realizada em grupos de 10 alunos, conduzidos à biblioteca, devidamente organizados para a realização dessa pesquisa e conforme disponibilidade da escola. Para melhor aproveitamento do material, foram dadas instruções verbais, a fim de que os alunos pudessem entender a dinâmica de como deveriam responder o instrumento. No questionário, as questões não remeteram diretamente ao bullying, porém, para melhor visualização e interpretação dos dados, os resultados foram apresentados com os termos bullying, vítimas, vítimas agressoras e agressores, conforme o contex to que envolve o fenômeno.

\subsection{Procedimentos de análise dos dados}

Os dados obtidos através da aplicação do questionário foram tabulados em planilhas do Excel, posteriormente transportados para o software SPSS (Statistical Package for the Social Sciences), aplicativo específico para análise estatística e apresentados em tabelas e gráficos que possibilitaram as análises descritivas. A fim de verificar a significância estatística dos dados, foram realizados testes estatísticos (Anova, Manova e Qui-quadrado), porém para a maioria dos resultados não foi possível a realização de inferências estatísticas, por se tratar de dados categóricos e não paramétricos. Para demonstrar a existência de diferenças estatisticamente significativas entre variáveis, foi utilizado como parâmetro o nível de significância ( $\mathrm{p}=0,05)$, que indica que o dado é considerado $95 \%$ verdadeiro.

No que diz respeito ao tipo de violência, as respostas dos alunos foram agrupadas de acordo com as categorias de bullying (físico; verbal; psicológico/moral; material; virtual ou sexual), citadas anteriormente.

Para caracterizar a ocorrência de bullying, na questão 8 (oito), foram consideradas somente as respostas: "quase todos os dias" ou "diariamente", pois de acordo com Pereira (2002) e Fante (2011), um fato isolado não pode ser caracterizado como bullying.

\section{RESULTADOS}

\subsection{Síntese dos dados de bullying}


SILVA, F.; DASCANIO, D; VALLE, T. G. M.

A Tab.1 apresenta os resultados sobre a ocorrência de bullying com 309 participantes de ambos os sexos, com idade de 11 a 15 anos.

Tabela 1 - Síntese dos dados de bullying

\begin{tabular}{ll|cc}
\hline & & $\boldsymbol{n}$ & $\mathbf{\%}$ \\
\hline $1-\quad$ Nunca sofreram algum tipo de violência & $\mathbf{9 1}$ & $\mathbf{2 9 , 5 \%}$ \\
$2-\quad$ Sofreram mas não configura bullying (1 ou 2 episódios) & $\mathbf{1 4 9}$ & $\mathbf{4 8 , 2 \%}$ \\
$3-\quad$ Vítimas & $\mathbf{6 1}$ & $\mathbf{1 9 , 7 \%}$ \\
$4-\quad$ Vítimas agressoras & $\mathbf{8}$ & $\mathbf{2 , 6 \%}$ \\
$5-\quad$ Agressores (retirados dos itens 1 e 2 da presente tabela) & 15 & $4,8 \%$ \\
Total da pesquisa & $\mathbf{3 0 9}$ & $\mathbf{1 0 0 \%}$ \\
Envolvidos com bullying (vítimas + vítimas agressoras & $\mathbf{8 4}$ & $\mathbf{2 7 \%}$ \\
+ agressores) & & \\
\hline
\end{tabular}

Fonte: Pesquisa de campo, 2013.

Do total dos 309 alunos participantes da pesquisa, 84 (27\%) se envolveram em episódios de bullying seja como vítima, vítima agressora ou agressor.

Dentre os $91(29,5 \%)$ participantes que nunca sofreram algum tipo de violência na escola, $6(6,5 \%)$ responderam ter como prática, "colocar apelidos ofensivos, xingar ou brigar" com outros alunos na escola, "quase todos os dias" ou "diariamente". Dos 149 $(48,2 \%)$ que responderam ter sofrido algum tipo de violência, mas não repetidas vezes (1 ou 2 vezes), o que não se configurou como bullying, foi possível identificar que 9 (6\%) foram autores de atos de bullying, isto é, agressores, somando $15(4,8 \%)$ agressores no total.

Dos $69(22,3 \%)$ alunos que disseram sofrer atos violentos repetitivamente (bullying), $8(2,6 \%)$ disseram praticar bullying contra outros colegas, ou seja, caracterizam-se como vítimas agressoras e 61(19,7\%) foram caracterizados somente como vítimas.

Referente aos 69 alunos que responderam ter sido vítima de bullying, 54\% (37) são do sexo feminino e $46 \%$ (32) do sexo masculino. A idade mais prevalente dos alunos vítimas de bullying é de 12 anos (27), seguida de 13 anos (16); 11 anos (15); 14 anos (9) e 15 anos (2). 


\subsection{Tipos de bullying sofrido por participantes do sexo masculino e do sexo feminino}

No instrumento de pesquisa, constam perguntas que oportunizaram respostas abertas e não limitadas a preencher somente um item, dessa forma, as respostas dadas pelos participantes do estudo ao questionário representam mais de um item. Percebe-se isso claramente na pergunta 6 (O que fazem ou já fizeram a você na escola?). Assim, a soma dos tipos apresentada na Fig.1, não resulta em 100\% devido essa possibilidade, porém, é possível verificar os tipos prevalentes.

Figura 1. Tipo de bullying sofrido por meninos e meninas.

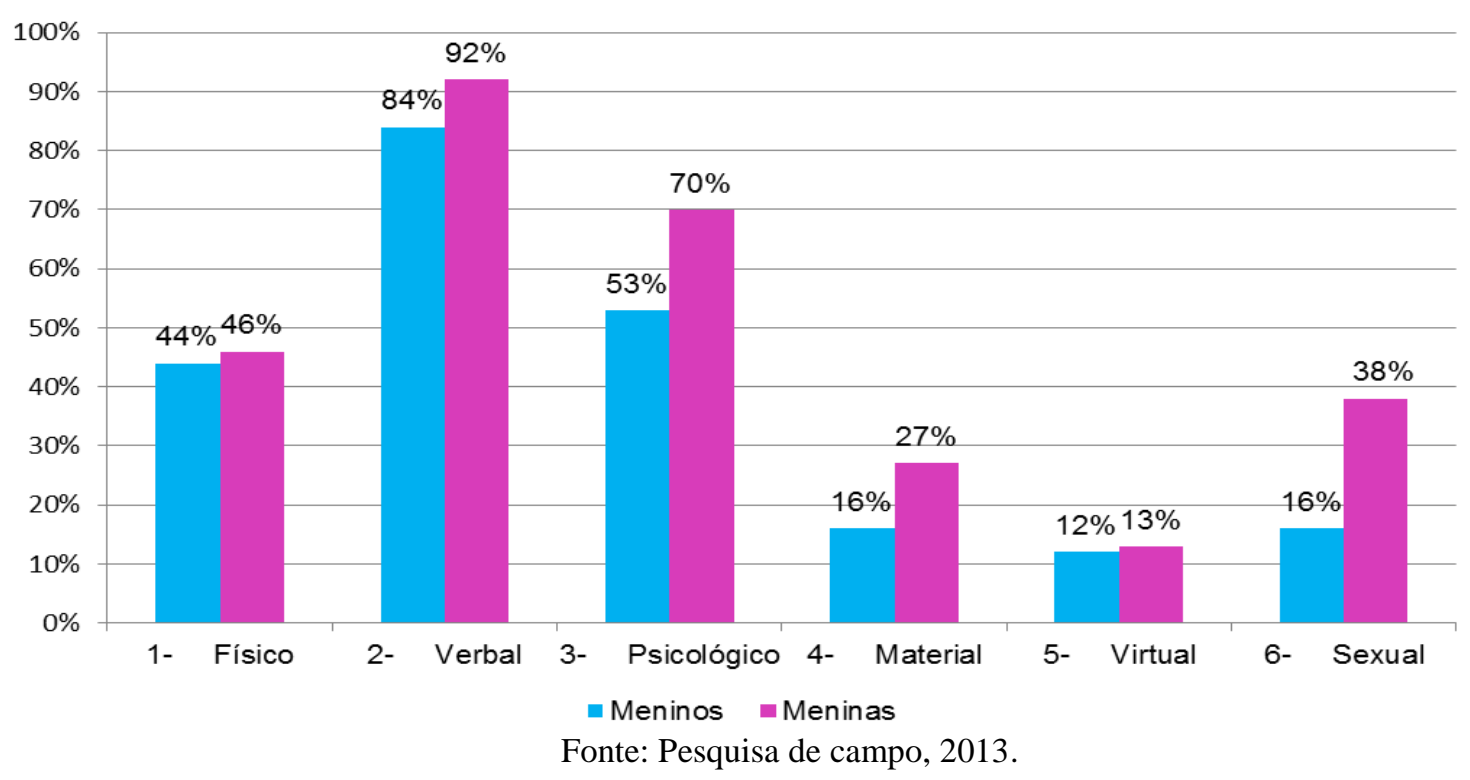

Na Fig.1, constam dados sobre os tipos de bullying mais sofridos por meninos e por meninas: bullying verbal - 92\% (34) meninas e $84 \%$ (27) meninos, seguido do tipo psicológico - 70\% (26) meninas e 53\% (17) sofrido por meninos. O tipo físico ocupa o $3^{\circ}$ lugar com $46 \%$ (17) das respostas das meninas e $44 \%$ (14) dos meninos, o material 27\% (10) pelas meninas e $16 \%$ (14) pelos meninos, o sexual é sofrido por 38\% (14) das participantes do sexo feminino e por $16 \%$ (5) do sexo masculino, o virtual está na última classificação, onde $13 \%$ (5) das meninas e 12\% (4) dos meninos sofreram esse tipo de violência.

Ao analisar estatisticamente essas diferenças, observa-se por meio do teste do Quiquadrado o $\left(\chi^{2}=4,24, p=0,04\right)$ que apenas para o tipo de bullying sexual (passar a mão em 
SILVA, F; DASCANIO, D; VALLE, T. G. M.

partes do corpo), foi encontrada diferença estatística significativa ao nível de 5\%, indicando que as meninas sofrem mais este tipo de bullying.

A pergunta 7 do questionário aplicado na pesquisa (Quem geralmente faz isso?) ofereceu dados referentes a quem é o agressor, isto é, quem pratica o bullying contra meninos e meninas, esses dados são demonstrados na Tab.2.

Tabela 2 - Quem pratica bullying contra meninos e meninas

\begin{tabular}{|c|c|c|c|c|c|c|}
\hline \multicolumn{3}{|c|}{ Quem sofre } & \multicolumn{4}{|c|}{ Quem agride } \\
\hline Escola & & $\mathbf{n}$ & Menino & Menina & Ambos & $\begin{array}{c}\text { Sem } \\
\text { resposta }\end{array}$ \\
\hline \multirow{2}{*}{$\begin{array}{l}\text { Municipal } \\
\text { (A) }\end{array}$} & Menino & 18 & $29 \%$ & $6 \%$ & $23 \%$ & $0 \%$ \\
\hline & Menina & 13 & $20 \%$ & $3 \%$ & $16 \%$ & $1 \%$ \\
\hline \multirow{2}{*}{$\begin{array}{l}\text { Estadual } \\
\text { (B) }\end{array}$} & Menino & 14 & $24 \%$ & $5 \%$ & $8 \%$ & $0 \%$ \\
\hline & Menina & 24 & $24 \%$ & $5 \%$ & $34 \%$ & $0 \%$ \\
\hline \multicolumn{3}{|c|}{ Total: 69 alunos } & & & & \\
\hline
\end{tabular}

Fonte: Pesquisa de campo, 2013.

Concernente a quem pratica o bullying, percebe-se que meninas e meninos são violentos. Devido ao fato de poderem assinalar concomitantemente duas respostas, ao analisar os dados da pergunta 7, uma nova categoria foi acrescentada: a categoria "ambos", pois os alunos responderam sofrer bullying tanto de meninos como de meninas. Ao analisar os dados da escola A (municipal), vê-se que o bullying sofrido pelos meninos é praticado por meninos em $29 \%$ (9) dos casos e praticado por meninas 6\% (2), conforme apresentado na Tabela 6. Quanto a quem pratica bullying contra meninas, $20 \%$ (6), é praticado por meninos e 3\% (1), por meninas. Na categoria "ambos", 23\% (7) dos meninos responderam ser agredidos por meninos e meninas e $16 \%$ (5) das meninas responderam que são agredidas por ambos. Somente uma menina deixou de responder à questão.

Na escola B (estadual), os resultados são bem semelhantes, o bullying sofrido por meninos é mais praticado por meninos, $24 \%$ (9), e praticado por meninas $5 \%$ (2). A maioria que pratica bullying contra meninas, são meninos, sendo eles mencionados por $24 \%$ (9) delas e $5 \%$ (2) das meninas dizem sofrer bullying praticado por meninas. Na categoria "ambos", $8 \%$ (3) das respostas foram de meninos e 34\% (13) de meninas. De modo geral, somando os 
resultados das duas escolas, excetuando a categoria ambos, meninos praticam bullying contra as meninas em 53\% (18) dos casos e contra meninos 44\% (15), e as meninas agridem $11 \%$ (4) das meninas participantes do estudo e $8 \%$ (3) dos meninos.

\title{
4 DISCUSSÃO DOS RESULTADOS
}

De acordo com o INEP (2014), existiam 15.036 alunos matriculados do $5^{\circ}$ ao $9^{\mathrm{a}}$ ano em escolas estaduais e municipais na cidade de Bauru - SP em 2014. Considerando que o estudo foi realizado somente em duas escolas, com apenas 162 alunos da escola municipal e 147 da escola estadual, percebe-se grande incidência de casos de bullying, pois os resultados apontam que $27 \%$ (84 alunos) da população estudada envolveu-se em episódios de bullying, seja no papel de vítima, vítima agressora ou agressor, conforme definição de Silva (2010). Saúde (2011), cita resultados de pesquisas européias em que a incidência dos casos de bullying oscila entre $10 \%$ e $30 \%$ da população estudada, dados que corroboram com os encontrados no presente estudo.

$\mathrm{Na}$ literatura, encontram-se pesquisas que afirmam que o bullying sofrido pelos meninos e meninas é diferente, pois elas apresentam formas mais sutis de agressividade como fofoca e os meninos, são mais agressivos fisicamente (OLWEUS, 2003; TRAUTMANN, 2008; MARTINS 2009).

Lisboa (2005, p.20), aponta que

\begin{abstract}
$\mathrm{Na}$ realidade, as diferenças entre os gêneros estão na forma de expressão da agressividade e não na função ou motivação da mesma. Não há razão ou evidência para acreditar que as mulheres são menos propensas a demonstrarem comportamento agressivo que os homens. As formas de comportamento agressivo podem estar relacionadas à aprendizagem social, considerando o papel social atribuído às mulheres nas culturas ocidentais.
\end{abstract}

Antes da aferição dos resultados, tinha-se como hipótese que as meninas sofriam mais bullying do tipo indireto (verbal, psicológico e virtual) e os meninos do tipo direto (físico, material e sexual), devido a estudos anteriores e fatores sociais e culturais, porém, meninos e meninas participantes deste estudo, respondeu em sua maioria que o tipo verbal (indireto) é o mais frequente, sendo $92 \%$ (34), de respostas femininas e $84 \%$ (27) masculinas. 
Em contraste, a pesquisa portuguesa de Melim e Pereira (2013), apontou os meninos como vítimas mais frequentes do bullying direto e as meninas no tipo indireto.

Ao apresentar o tipo de bullying sofrido, percebe-se que em todas as categorias destacam-se mais vítimas entre as meninas. Mesmo que não haja uma diferença estatisticamente significativa, exceto no tipo sexual (passar a mão em partes do corpo), os dados gerais sobre bullying são importantes e apontam que as meninas são mais agredidas. Neste sentido, Fante (2011), em um de seus estudos, no qual participaram 450 alunos do interior do Estado de São Paulo, relata que 10\% dos participantes, foram vítimas de abusos sexuais (passar a mão nas genitálias masculinas ou femininas, nádegas e seios).

Saúde (2011), em sua revisão bibliográfica, concluiu que vários autores encontraram diferenças significativas entre condutas agressivas e o gênero, mas isso deve ser considerado como uma predominância e não como uma regra, em que meninos se utilizam somente de violência direta e as meninas de forma indireta, visto que a agressão verbal, tende a ser a tipologia mais utilizada por ambos os gêneros, o que pôde ser confirmado com os dados deste estudo. Pode-se atribuir esse resultado aos valores da sociedade moderna, na qual as mulheres buscam cada vez mais equiparar-se aos homens.

Embora o teste estatístico Manova tenha resultado diferença significativa entre quem faz bullying e o tipo virtual $(F=3,29 ; p=0,02)$, mesmo sendo uma geração que convive conectada a redes sociais e em contato constante com a Internet e celulares, esse tipo foi o menos mencionado pelos participantes, onde somente $12 \%$ (4) dos meninos e $13 \%$ (5) das meninas responderam ter sofrido bullying virtual.

Pesquisas revelam que os meninos geralmente agridem meninos e meninas, enquanto elas agridem meninas. Meninos utilizam mais agressão física, ameaça verbal e são mais apontados como agressores. As meninas se utilizam de estratégias mais "leves" como fofocas, apelidos, ignorar, excluir do grupo e oferecem mais suporte as vítimas (SHARP, SMITH, 1991; BOULTON, UNDERWOOD, 1992; GINI, POZZOLI, 2006). Tais achados descritos na literatura foram confirmados com esta pesquisa, pois 54\% (37) das vítimas, são do sexo feminino e $46 \%$ (32), do sexo masculino; ambos agredidos mais por meninos que por meninas. Estes resultados também foram apontados por Bandeira (2009), onde os meninos envolvem-se em mais episódios de bullying, sendo apontados mais frequentemente na condição de agressores do que as meninas. 
Seixas (2009) justifica que a diferença entre os comportamentos se dá porque as meninas adquirem competências sociais de empatia e reconhecimento de vozes e rostos desde muito pequenas e suas brincadeiras (boneca, casinha) estão relacionadas a interações sociais e verbais, e os meninos escolhem e aprendem culturalmente brincadeiras físicas e mecânicas (lutas, bola, carrinhos).

Gómez Sanabria et al. (2007), concluíram em sua pesquisa, que existem mais agressores e vítimas entre os meninos e que são atacados apenas por meninos, enquanto as meninas, são agredidas tanto por meninas quanto por meninos. No presente estudo, considerando os dados isoladamente, sem contar com a categoria ambos, 53\% (18) dos meninos, sofrem bullying praticado por meninos e 11\% (4) deles, foram agredidos por meninas. Enquanto 44\% (15) das meninas participantes são agredidas por meninos e 8\% (3) por meninas. Os dados divergem do estudo de Gómez Sanabria et al. (2007), pelo fato de os garotos serem agredidos por ambos os sexos e não exclusivamente por garotos.

Fato que confirma as pesquisas anteriores, em que os autores concluíram que as meninas são mais vítimas do que os meninos (OLWEUS, 2003; LIANG, FLISHER, LOMBARD, 2007). Uma variável que pode ter influenciado nos resultados: a escola municipal (A) é menor, tanto em espaço físico, quanto em quantidade de alunos por série; o que pode facilitar a supervisão dos alunos pelos professores e funcionários.

\section{CONSIDERAÇÕES FINAIS}

Por meio do instrumento utilizado foi possível identificar vítimas, vítimas agressoras e agressores, porém, o mesmo ao basear-se no relato em vez de observação direta dos comportamentos, o pesquisador torna-se dependente da capacidade dos participantes no que se refere a discriminação do que sejam comportamentos agressivos ou não e também contar com a memória dos mesmos para lembrarem quantas vezes mesmo sofreram agressões, o que pode ter interferido nos resultados.

Não obstante as contribuições deste estudo, também são reconhecidas suas limitações, desta forma, ao elaborar um instrumento próprio, correu-se o risco de enfrentar situações imprevisíveis, porém, mesmo observando certas limitações, os objetivos propostos foram alcançados. 
O Estudo Piloto favoreceu diferentes aspectos na fase da elaboração, mas o instrumento, não foi submetido a juízes da área, para melhor refinamento das informações. $\mathrm{Na}$ questão 8 (Quantas vezes isso acontece ou aconteceu neste ano?), por exemplo, detectou-se que as opções ficaram muito distantes, pois há um salto entre as respostas "1 vez", "2 vezes" e "quase todos os dias" e "diariamente", assim, para novos estudos, as opções devem ser revistas no sentido de oferecer alternativas que possam ser aferidas com maior precisão.

Observou-se durante a organização dos resultados, que para novos estudos que envolvam personagens de bullying, pode ser enriquecedor explorar os sentimentos desses alunos, saber o que o agressor sente ao prejudicar direta ou indiretamente um colega ou, o que sente a vítima. $\mathrm{O}$ instrumento não subsidiou a identificação do personagem espectador, que no fenômeno é muito importante, pois com seu apoio e suas risadas reforça as atitudes do agressor e na maioria dos casos omite ajuda as vítimas. Essas informações poderão auxiliar no oferecimento de estratégias de enfrentamento, autocontrole, entre outros.

Ainda que novas pesquisas sejam necessárias, certamente os dados aqui apresentados, podem proporcionar aspectos de reflexão para profissionais da educação, para que transformem o ambiente escolar, num contexto mais igualitário, através de ações que visem o respeito às diferenças, a empatia e valorização das amizades. $\mathrm{O}$ fato de meninas também agredirem fisicamente, o que diverge da literatura encontrada, traz aos novos pesquisadores novas informações e pistas para trabalharem com mais profundidade o assunto.

Ao chamar a atenção para aspectos relevantes sobre o bullying, as consequências para vítimas e agressores e que o fenômeno é realidade em muitas escolas, visa-se que instituições escolares e professores possam oferecer alternativas para a construção de uma escola que resgate os valores próprios de uma sociedade inclusiva.

Conter a indisciplina e conflitos através de punições e advertências não é o caminho para se obter a paz nas escolas. Desenvolver atitudes de democracia, valorização das amizades, respeito ao próximo, aos familiares e as regras, contribuirá para o desenvolvimento de cidadãos que farão a diferença na comunidade em que estiverem inseridos.

A escola do sonho é aquela em que o professor é bem remunerado, valorizado, ciente de seu papel, que considera as potencialidades do aluno, explora sua criticidade, auxilia nas suas dificuldades, contribui para elevar a autoestima do estudante e constrói um clima de respeito mútuo e tolerância às diferenças. Ali, os alunos prestam atenção nas instruções, realizam suas tarefas, ajudam-se mutuamente, estão preocupados com sua aprendizagem e 
como poderão colocar seus conhecimentos em prática em prol da humanidade. Vamos tornála real?

\title{
THE BULLYING PHENOMENON: DIFFERENCES BETWEEN BOYS AND GIRLS
}

\begin{abstract}
The bullying phenomenon is characterized by aggression always unequal power and involves violence. This study aimed to identify the types of bullying (physical, verbal, psychological, material, virtual or sexual) more prevalent in this population and compare bullying among adolescent males and females. We used a questionnaire prepared by the researcher. Participants were 309 students, 142 males and 167 females, from 6th to 8th grade from two schools, one state and one municipal. These results show $27 \%$ of participants were involved in episodes of bullying and that the most prevalent type of bullying was verbal, being appointed for $92 \%$ of girls and $84 \%$ boys; followed by psychological, indicated by $70 \%$ of girls and $53 \%$ boys. Physical bullying, had $46 \%$ of female and $44 \%$ male reports, the material was mentioned by $27 \%$ of girls and $16 \%$ boys. On sexual bullying type was greatest difference between the sexes, suffered by $38 \%$ of girls and $16 \%$ boys. Only $13 \%$ of girls and $12 \%$ boys, mentioned suffer the virtual bullying. Corroborating research area, in this study the highest percentage of victims were female and different from the literature girls reported being verbally abused more for boys than for girls.
\end{abstract}

Keywords: School Bullying; Peer Violence; Difference Between Sexes

\section{EL FENÓMENO BULLYING: DIFERENCIAS ENTRE NIÑOS Y NIÑAS}

\section{Resumen}

El fenómeno bullying se caracteriza por la agresión siempre poder desigual e implica violencia. Este estudio tuvo como objetivo identificar los tipos de acoso escolar (física, verbal, psicológica, material virtual o sexual) más frecuente en esta población y comparar la intimidación entre los adolescentes varones y mujeres. Se utilizó para recopilar datos, un cuestionario elaborado por el investigador. Participó del estudio 309 estudiantes, 142 niños y 167 niñas, del 6 al 8 de grado de dos escuelas, un estado y un municipal. Los resultados 
SILVA, F; DASCANIO, D; VALLE, T. G. M.

mostraron un $27 \%$ de los encuestados estaban involucrados en episodios de intimidación y que el tipo más frecuente de intimidación fue verbal, siendo nombrado el $92 \%$ de las niñas y $84 \%$ niños; seguido de psicológica, indicado por el $70 \%$ de las niñas y $53 \%$ niños. La intimidación física, tenía $46 \%$ de los informes de hombres y mujeres y el $44 \%$, el material fue mencionado por el $27 \%$ de las niñas y $16 \%$ niños. Por tipo de acoso sexual fue mayor diferencia entre los sexos, que sufre el $38 \%$ de las niñas y $16 \%$ niños. Sólo el $13 \%$ de las niñas y $12 \%$ niños, mencionadas sufren el acoso virtual. Corroborando área de investigación, en este estudio el porcentaje más alto de las víctimas eran mujeres y diferente de la literatura las chicas reportaron haber sido insultado más los niños que en las niñas.

Palabras clave: Acoso Escolar; La violencia entre Pares; Diferencia entre Sexos

\section{REFERÊNCIAS}

ALMEIDA, A.; LISBOA, C.; CAURCEL, M. J. ¿Por qué ocurren los malos tratos entre iguales? Explicaciones causales de adolescentes portugueses y brasileños. Revista Interamericana de Psicologia, v.41, n.2, p.107-118, 2007.

BALDRY, A.C.; FARRINGTON, D.P. Bullies and delinquents: Personal characteristics and parental styles. Journal of Community and Applied Social Psychology, v. 10, p.17-31, 2000. doi: http://dx.doi.org/10.1002/(sici)1099-1298(200001/02)10:1\%3C17::aidcasp526\%3E3.0.co;2-m

BANDEIRA, Cláudia de Moraes. Bullying: autoestima e diferenças de gênero. 2009. 69 p. Dissertação (Mestrado em Psicologia). Instituto de Psicologia, Universidade Federal do Rio Grande do Sul, Porto Alegre. 2009.

BINSFELD. A. R.; LISBOA, C. S. M. Bullying: Um estudo sobre papéis sociais, ansiedade e depressão no contexto escolar do Sul do Brasil. Interpersona. v. 4, n. 1, p. 74-105, 2010. doi: http://dx.doi.org/10.5964/ijpr.v4i1.44

BOULTON, M. J.; UNDERWOOD, K. Bully/victim problems among middle school children. British Journal Educational Psychology, 62, p.73-87. 1992. doi: http://dx.doi.org/10.2753/eue1056-4934250318

CALHAU, Lélio Braga. Bullying: O que você precisa saber: identificação, prevenção e repressão. $2^{\mathrm{a}}$ ed. Niterói, RJ: Impetus, 2010.

CID, H. P.; DÍAZ M, A.; PÉREZ, M. V.; TORRUELLA, P. M.; VALDERRAMA, A. M. 
Agressión y violência em la escuela como factor de riesgo del aprendizaje escolar. Ciencia y Enfermeria, v.14, n.2, p.21-30, 2008. doi: http://dx.doi.org/10.4067/s071795532008000200004

ESPERON, P.S.M. Bullying - Comportamento agressivo entre colegas no ambiente escolar. Pediatria Moderna, v. XL, n.2, p.69-76, abril-mar, 2004.

FANTE, Cleo. Fenômeno Bullying. Como prevenir a violência nas escolas e educar para a paz. $6^{\text {a }}$ ed. Campinas: Verus, 2011.

FRANCISCO, Marcos Vinicius. Percepções e formas de enfrentamento de adolescentes frente ao bullying. 2010. 114 p. Dissertação (Mestrado em Educação) Faculdade de Ciências e Tecnologia. Presidente Prudente, 2010.

FREIRE, I. P.; SIMÃO, A. M. V.; FERREIRA, A. S. O estudo da violência entre pares no $3^{\circ}$ ciclo do ensino básico - um questionário aferido para a população escolar portuguesa. Revista Portuguesa de Educação, v.19, n.2, p. 157-183. 2006.

FRICK, L.T.; MENIN, M.S.S.; TOGNETTA, L.R.P. Um estudo sobre as relações entre os conflitos interpessoais e o bullying entre escolares. Revista Reflexão e Ação, Santa Cruz do Sul, v.21, n.1, p.93-113, jan./jun.2013

GINI, G.; POZZOLI, T. The role of masculinity in children's bullying. Sex Roles, v. 54, p. 585-588. Italy, 2006. doi: http://dx.doi.org/10.1007/s11199-006-9015-1

GÓMEZ SANABRIA, A.; GALA, F.J.; LUPIANI, M.; BERNALTE, A.; MIRET, M.T.; LUPIANI, S.; BARRETO, M.C. El "bullying" y otras formas de violencia adolescente. Cuad Med Forense, 13(48-49), Abr-Jul, 2007. doi: http://dx.doi.org/10.4321/s113576062007000200005

INEP. Instituto Nacional de Estudos e Pesquisas Educacionais Anísio Teixeira. Resultados Finais do Censo Escolar 2014. Disponível em <http://portal.inep.gov.br/basica-censo-escolar-matricula>. Acesso em: 05 fev. 2015.

LIANG, H., FLISHER, A. J., LOMBARD, C. J. Bullying, violence and risk behavior in South African school students. Child Abuse \& Neglect, v. 31, p. 161-171, 2007. doi:

http://dx.doi.org/10.1016/j.chiabu.2006.08.007

LISBOA, Carolina Saraiva de Macedo. (2005). Comportamento agressivo, vitimização e relações de amizade em crianças em idade escolar: fatores de risco e proteção. Tese de Doutorado, Programa de Pós-Graduação em Psicologia do Desenvolvimento, Instituto de Psicologia, Universidade Federal do Rio Grande do Sul, Porto Alegre.

LOPES NETO, Aramis. Bullying: Comportamento agressivo entre estudantes. Jornal de Pediatria. v. 81 , n. 5. p. 164-172, Rio de janeiro: SBP, 2005. doi: http://dx.doi.org/10.1590/s0021-75572005000700006 . Bullying: Saber identificar e como prevenir. São Paulo: Brasiliense, 2011. 
SILVA, F; DASCANIO, D; VALLE, T. G. M.

LOPES NETO, A; SAAVEDRA, L. H. Diga não para o bullying - programa de redução do comportamento agressivo entre estudantes. Rio de Janeiro: ABRAPIA, 2004.

MARTINS, Maria José D. Mau-tratos entre adolescents na escola. Lisboa: Editorial, 2009.

MELIM, M.; PEREIRA, B. (2013) Bullying, Género e Idade. In P. SILVA S. SOUZA, I.

NETO (Eds.). O desenvolvimento humano: perspectivas para o século XXI-Memória, Lazer e Atuação Profissional. Volume 1 (292-316). São Luís:

EDUFMA.

NOGUEIRA, R.M.C.D.P.A. Violências nas escolas e juventude: um estudo sobre o bullying escolar. 2007. 258 p. Tese (Doutorado em Educação). Programa de Pós-graduação em Educação: História, Política e Sociedade. Pontifícia Universidade Católica de São Paulo, São Paulo. 2007.

OLIVEIRA, Juliana Munaretti. Indícios de casos de Bullying no Ensino Médio de Araraquara - SP. 2007. 110 p. Dissertação (Mestrado do Programa de Pós-graduação em Desenvolvimento Regional e Meio Ambiente). UNIARA, Centro Universitário de Araraquara, Araraquara. 2007.

OLWEUS, Dan. Bullying at school: What we know and what we can do. London: Blackwell, 1993.

. Acoso Escolar, “Bullying”, en las escuelas: hechos e intervenciones. Centro de investigación para la promoción de la salud, Universidade de Berger, Noruega, 2003.

. Conductas de acoso y amenaza entre escolares. 3. ed. Madrid: Ediciones Morata, 2006.

PEREIRA, Beatriz Oliveira. Para uma escola sem violência: estudo e prevenção das práticas agressivas entre crianças. Fundação Calouste Gulbenkian, Ministério da Ciência e Tecnologia: Lisboa, 2002.

ROLIM, Marcos. Bullying: O pesadelo da escola, um estudo de caso e notas sobre o que fazer. 2008. 174 p. Dissertação (Mestrado em Sociologia). Instituto de Sociologia, Universidade Federal do Rio Grande do Sul, Porto Alegre. 2008.

SANTA CATARINA (Estado). Lei 14.641/09 de 12 de janeiro de 2009. Institui o Programa de Combate ao Bullying, de ação interdisciplinar e de participação comunitária nas escolas públicas e privadas do Estado de Santa Catarina. Santa Catarina, 2009.

SANTOS, Ana Paula Toppan. A presença do bullying na mídia cinematográfica como contribuição para a educação. 2009. 237 p. Dissertação (Mestrado em Comunicação, Mídia e Cultura). Faculdade de Comunicação e Educação. Universidade de Marília, Marília. 2009. 
SANTOS, Elisabete Gonçalves. Empatia e Bullying, em alunos do 4. ${ }^{\circ}$ e do 6. ${ }^{\circ}$ ano. 2011. p. 110. Dissertação (Mestrado em Educação). Instituto de Educação, Universidade de Lisboa, Lisboa. 2011.

SAÚDE, Ana. Catarina. Bullying e Bem-estar Psicológico em alunos dos $2^{\circ}$ e $3^{\circ}$ Ciclos do Ensino Básico e Secundário. 2011. 146 p. Dissertação (Mestrado de Psicologia da Educação). Faculdade de Psicologia. Universidade Lusófona de Humanidades e Tecnologias, Lisboa. 2011.

SEIXAS, Sónia Raquel. Diferenças de género nos comportamentos de bullying: contributos da neurobiologia. Interaçções. n.3, p. 63-97. 2009.

SHARP, S., SMITH, P. K. Bullying in UK schools: The DES Sheffield Bullying Project. Early Child hood Development and Care, v.77, p. 47-55. 1991. doi:

http://dx.doi.org/10.1080/0300443910770104

SILVA, Ana Beatriz Barboza. Bullying: mentes perigosas na escola. Rio de Janeiro: Objetiva, 2010.

TOGNETTA, Luciene Regina Paulino. Violência da escola x violência na escola. In: Anais do VIII Congresso Nacional de Educação da PUCPR - EDUCERE e o III Congresso IberoAmericano sobre Violências nas Escolas - CIAVE. Curitiba: Pontifícia Universidade Católica, PUC, 2008.

TRAUTMANN, Alberto. Maltrato entre pares o "bullying”. Una visión actual. Revista Chilena de Pediatría, 79 (1), 13-20, 2008. doi: http://dx.doi.org/10.4067/s037041062008000100002

Data de recebimento: 29/01/2016

Data de aceite: 07/03/2016 